\title{
Reliability of Questionnaires to Assess the Healthy Eating and Activity Environment of a Child's Home and School
}

\author{
Annabelle Wilson, ${ }^{1,2}$ Anthea Magarey, ${ }^{1}$ and Nadia Mastersson ${ }^{3}$ \\ ${ }^{1}$ Nutrition and Dietetics, Flinders University of South Australia, GPO Box 2100, Adelaide, SA 5001, Australia \\ ${ }^{2}$ Discipline of Public Health, Flinders University of South Australia, GPO Box 2100, Adelaide, SA 5001, Australia \\ ${ }^{3}$ Health Promotion Branch, SA Health, Government of South Australia, P.O. Box 287 Adelaide, SA 5000, Australia \\ Correspondence should be addressed to Anthea Magarey; anthea.magarey@flinders.edu.au
}

Received 6 December 2012; Revised 8 May 2013; Accepted 6 June 2013

Academic Editor: Sarah McNaughton

Copyright (C) 2013 Annabelle Wilson et al. This is an open access article distributed under the Creative Commons Attribution License, which permits unrestricted use, distribution, and reproduction in any medium, provided the original work is properly cited.

\begin{abstract}
Childhood overweight and obesity are a growing concern globally, and environments, including the home and school, can contribute to this epidemic. This paper assesses the reliability of two questionnaires (parent and teacher) used in the evaluation of a community-based childhood obesity prevention intervention, the eat well be active (ewba) Community Programs. Parents and teachers were recruited from two primary schools and they completed the same questionnaire twice in 2008 and 2009 . Data from both questionnaires were classified into outcomes relevant to healthy eating and activity, and target outcomes, based on the goals of the ewba Community Programs, were identified. Fourteen and 12 outcomes were developed from the parent and teacher questionnaires, respectively. Sixty parents and 28 teachers participated in the reliability study. Intraclass correlation coefficients for outcomes ranged from 0.37 to 0.92 (parent) $(P<0.05)$ and from 0.42 to 0.86 (teacher $)(P<0.05)$. Internal consistency, measured by Cronbach's alpha, of teacher scores ranged from 0.11 to 0.91 and 0.13 to 0.78 for scores from the parent questionnaire. The parent and teacher questionnaires are moderately reliable tools for simultaneously assessing child intakes, environments, attitudes, and knowledge associated with healthy eating and physical activity in the home and school and may be useful for evaluation of similar programs.
\end{abstract}

\section{Introduction}

Overweight and obesity are a global concern in both developed and developing countries and in school age children, the prevalence continues to remain high. Australian childhood overweight and obesity rates have been shown to be $25.3 \%$ for boys and girls aged 5-17 years, comprised of $17.7 \%$ overweight and $7.6 \%$ obese [1]. There is a clear need for effective prevention efforts to address the high prevalence of childhood and adult obesity [2] without which obesity will become the primary cause of preventative deaths worldwide [3].

Management of this epidemic requires action at a number of levels including broad-based community interventions that focus on environmental change to support individual behaviours [4-6]. Governments need to contribute to less obesogenic environments through political, physical, sociocultural and structural change, and prevention programs $[2,7,8]$. Despite a large body of the literature pertaining to the management of childhood obesity, there are a limited but increasing number of community-wide prevention projects. To effectively target childhood obesity, existing and new programs need to be systematically evaluated to determine the efficacy of the implemented strategies and such evaluations should be of high quality in order to contribute to the evidence for addressing childhood obesity [9]. However, these evaluations are limited by a lack of setting specific tools which allow evaluation specific to a particular setting, such as a school or home environment [10], and further limited by a lack of reliable tools suitable for evaluation purposes in these settings.

The eat well be active (ewba) Community Programs were implemented in South Australia from 2005 to 2010, focusing on prevention of obesity through environmental change 
using a community development approach. Details of this program have been published [10-15]. Briefly, the program aimed to increase the proportion of $0-18$ year old children within the healthy weight range by effecting environmental change which in turn would influence healthy eating and physical activity behaviours. A comprehensive evaluation framework was included in the program [12]. Results from the evaluation of ewba have been reported elsewhere [12-15].

Due to the lack of relevant tools to evaluate the impact of the intervention, a number of program-specific questionnaires were developed to assess behaviours, knowledge, attitudes, and environments relevant to the goals of the program of increasing healthy eating and activity. Four of these tools were completed by children aged 9 to 11 years, their parents, and teachers. A critical factor in the use of any tool is its reliability. Assessment of these tool properties is important to ensure that accurate and appropriate assessments can be conducted [16]. The reliability and internal validity of the Child Nutrition Questionnaire have been reported [10].

The aim of this paper is to report the reliability of the parent and teacher questionnaires, tools that assess the diet and physical activity environments of children in the home and school, respectively. These questionnaires can provide relevant insight into the domains which influence nutrition and physical activity behaviours in children, and may be used to evaluate obesity prevention interventions.

\section{Methods}

Ethics approval for this study was obtained from the Flinders University Social and Behavioural Research Ethics Committee, the South Australian Health Ethics Committee, and the Department of Education and Children's Services Ethics Committee.

2.1. Subjects. Subjects were recruited from two schools. School 1 was a reception-Year 12 (5-18 years) government school in the north of Adelaide and School 2 a ReceptionYear 12 Catholic school in a regional centre in South Australia. School 2 was part of the wider ewba evaluation, but School 1 was not. All parents of children in years 5-7 at School 1 were invited to participate in the test-retest reliability study, and all teachers were invited at a staff meeting, in October 2008. At School 2, the test-retest reliability study was conducted in conjunction with the ewba follow-up evaluation. Parents who participated in this ewba evaluation follow-up (Sept-Nov 2009) were invited by letter to complete the questionnaire on a second occasion, and all teachers were asked at a staff meeting to complete the survey a second time.

At School 1, Test 1 was administered to all teachers at a staff meeting. At School 2, Test 1 was administered to teachers who agreed to participate whose classes were participating in the wider ewba evaluation. At School 1, the parent questionnaires were sent home by the school to all parents of students in school years five, six, and seven. An introductory letter, an information sheet, and replypaid envelope to allow return by post accompanied the questionnaire. At School 2, the parent questionnaires were administered as part of the wider ewba evaluation, as reported in [11]. Two weeks later at both schools, teachers completed the questionnaire again at a staff meeting, and parents who completed the first questionnaire were mailed the second questionnaire with a reply-paid envelope. Reminder letters were sent two weeks later by the school to parents who had not returned the second questionnaire. Both questionnaires took approximately 20 minutes to complete.

2.2. Development of Questionnaires. The parent and teacher questionnaires were part of a suite of questionnaires developed for evaluation of the ewba Community Programs. The questionnaires were developed by the program evaluation committee which included academics with expertise in childhood obesity, nutrition, physical activity, and community development. These were developed in response to a lack of valid and relevant tools being available in the published or the grey literature. The items included in the program-specific questionnaires were specifically selected to evaluate each of the program's relevant objectives. Thus, these questionnaires were likely to be more sensitive to the programs' goals and objectives than any existing questionnaires which were more general and did not include the breadth of the programs' inquiry.

The parent questionnaire contains 25 questions requiring 67 responses covering the following domains: demographics; obesogenicity of the home environment; parental knowledge and attitudes towards healthy eating and physical activity; child physical activity and healthy eating behaviours. Two additional questions ask about food security and difficulty of breastfeeding in public places (Table 1). The teacher questionnaire consists of 15 questions requiring 44 responses covering teaching practices around healthy eating and physical activity inclusion in the school curriculum; training/experience in healthy eating and physical activity; teacher knowledge and attitudes towards healthy eating and physical activity (Table 2).

2.3. Scoring the Questionnaires. To produce more meaningful and reliable results, some responses are condensed into "scores" by summing items which represent a specific domain. This is one way of interpreting information obtained from dietary indexes and has been used previously [10,17-19]. In order to make the analyses specific to ewba and to be able to measure the impact of the intervention directly by relating to the specific project goals, items were grouped into scores based on the goals of the ewba Community Programs. For example, goals related to diet included decreasing child intake of sweetened beverages and noncore foods and increasing intake of water and fruit and vegetables; hence, these were used as categories for the basis of developing scores related to child intake. Similarly, goals related to physical activity were increasing active pastimes and decreasing sedentary activity; hence, these were used as the basis for classifying items into scores demonstrating child physical activity. Generally, ewba sought to influence at multiple levels including attitudes, behaviours, and environments; therefore, scores assessed one of these three domains in the context of the diet or activity 


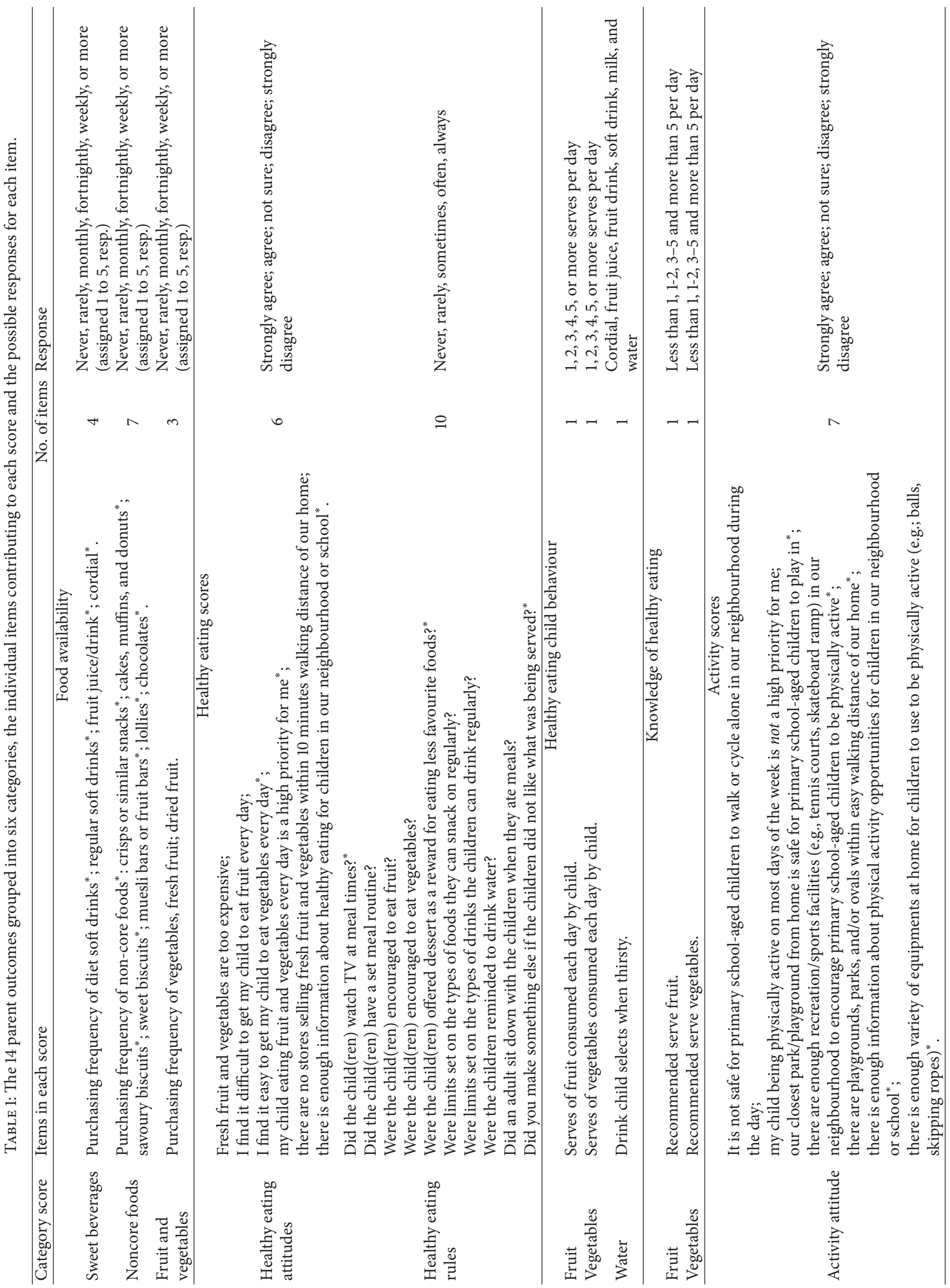




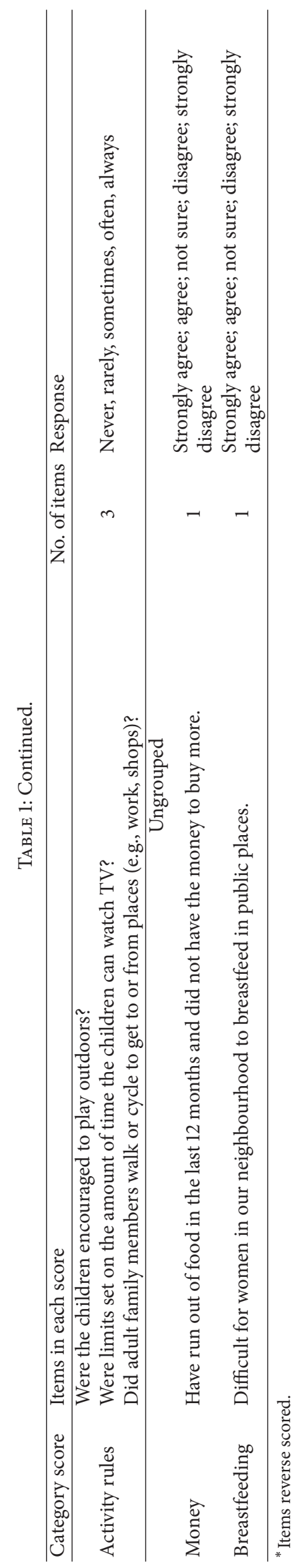




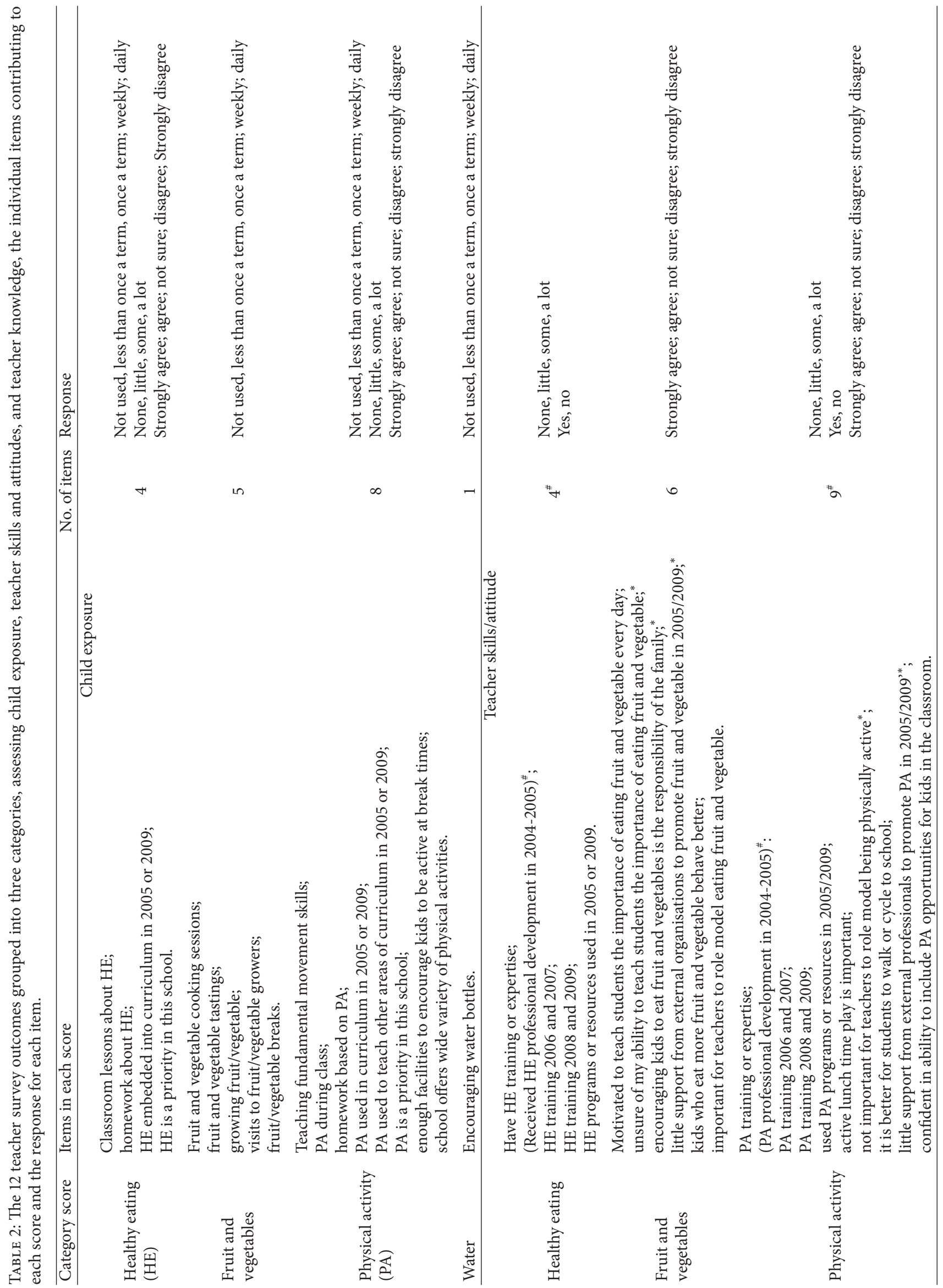




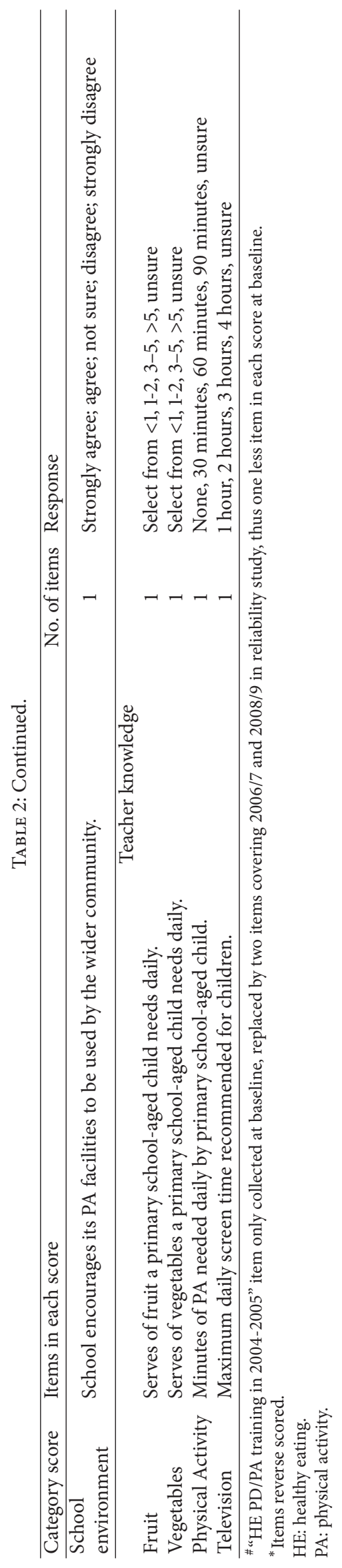


factors mentioned previously (non-core food, sweetened beverages, water, fruit and vegetables, active pastimes, and sedentary pastimes). Items were reverse coded where necessary, so a higher score represented a more positive attitude or behaviour. The created scores allow better assessment of health themes, enablers, and barriers and can be used to compare baseline data against a "target" score. Outcomes that could not be grouped into a score are left as single items. Thus, there are 14 outcomes (seven scores and seven single items) from the parent questionnaire and 12 outcomes (six scores and six single items) from the teacher questionnaire. A target score which identifies a healthy attitude or environment was determined for each score (Tables 3 and 4). Targets for assessment of intake were largely based on the Australian Guide to Healthy Eating (AGHE) [20]. Assessment of physical activity was based on the Physical Activity Guidelines for five to 12 year olds [21] and 12 to 18 year olds [22].

2.4. Statistical Analysis. All data were analysed using SPSS 18.0.1. (SPSS Inc.) Statistical significance was accepted at $P \leq$ 0.05 . The 14 parent and 12 teacher outcomes were assessed for test-retest reliability using the intraclass correlation coefficient (ICC). Internal consistency of the teacher and parent scores (outcomes with multiple items; parent questionnaire seven scores; teacher questionnaire 6 scores) at Time 1 was assessed using Cronbach's alpha.

\section{Results}

3.1. Parent Questionnaire Test-Retest Reliability. Sixty parents (School 1: 22, School 2: 38) completed the questionnaire on two occasions one to two weeks apart. All but one respondent was female, $46(77 \%)$ were married or in a defacto relationship, half ( $n=33,55 \%)$ were from two children households, 13 (22\%) had a university degree, and two (3\%) had Year 10 schooling or less. Forty-six (77\%) were working full-or part-time, and 20 (33\%) held a government health care card. It is not possible to calculate response rates for parents at both schools as questionnaires were posted to parents by the school and exact numbers posted are unknown. Table 3 shows the outcomes for each questionnaire and the ICC (95\% confidence interval) for each score. All ICCs were statistically significant and ranged from 0.37 to 0.92 with eight of the fourteen greater than 0.7. Cronbach's alpha varied from 0.13 to 0.78 for the scores from the parent questionnaire, with three of seven scores having alpha values greater than 0.5 .

3.2. Teacher Questionnaire Test-Retest Reliability. Twentyeight teachers (School 1: 24, School 2: 4) completed the teacher questionnaire twice. This is a response rate of $100 \%$ at School 1 and 50\% at School 2. Most $(n=23)$ were female, and a majority taught across multiple year levels with half the respondents teaching in each of Reception to Year 5 and approximately one third teaching Year 6. Thirteen respondents had been at their current school for four years or longer, and for eight, it was their first year at the school. Table 4 shows the outcomes for each completion of the questionnaire and the ICC (95\% confidence interval) for each score. All ICCs were statistically significant and ranged from 0.42 to 0.86 with five of the twelve greater than 0.7 . Cronbach's alpha varied from 0.11 to 0.91 for the scores from the teacher questionnaire, with four of six scores having alpha values greater than 0.5 .

\section{Discussion}

The purpose of this study was to determine the reliability of the parent and teacher questionnaires developed to evaluate the ewba Community Programs, two questionnaires that assess the healthy eating and physical activity environments of children. The parent questionnaire assesses child dietary intakes, parent knowledge of health-related recommendations, and attitudes about healthy behaviours. The teacher questionnaire assesses the degree to which teachers incorporate healthy eating and activity facets in their daily teaching regime and their skills, attitudes, and knowledge around healthy eating and physical activity.

Overall the surveys showed good test-retest reliability with only one outcome in each of the parent and teacher surveys having an ICC of less than 0.5 (parent,-money, and teacher, knowledge (fruit)). The test-retest reliability of knowledge questions in both the parent and teacher surveys was generally lower than the other items, with ICCs between 0.4 and 0.6. One possible reason for this is the difficulty determining which recommendations to use. The commonly promoted message in South Australia is "Go for $2 \& 5$ " which are the adult recommendations for fruit and vegetable intake, respectively, and a message that is actively used in schools. However, the AGHE recommends a minimum of one and three serves of fruit and vegetables, respectively, for 8-11 year olds and two and four serves, respectively, for 12-18 year olds [20]. The AGHE includes additional options according to varying eating patterns with serves above these minimums. The response options aimed to cover these varying recommendations. These different messages are a potential source of confusion which may mean that respondents are "guessing" the correct option and this in turn would be a source of retest error.

The internal consistency of the scores in the parent and teacher questionnaires was poor to moderate. It is recommended that Cronbach's alpha is greater than 0.7 [23]. Only one score from the parent questionnaire (non-core food) and three from the teacher questionnaire were in line with this recommendation; however, the value is affected by the number of items in the scale, and it is common to find low Cronbach's alpha values with scales with less than ten items [24]. Four scores from the parent questionnaire had between five and ten items and three scores had less than five items. In the teacher questionnaire, four scores had between five and nine items and two scores had less than five items. Hence, the low number of items in the scores could be a reason for the poor to moderate internal consistency observed. Furthermore, the parent and teacher scores were created by summing items that measure the goals of the ewba program, specifically reducing intake of noncore foods and sweetened beverages, reducing screen time, and increasing 
TABLE 3: Reliability $\left(n=60^{\dagger}\right)$ demonstrated by intraclass correlation coefficient (ICC) and $95 \%$ confidence intervals (CI) for the parent outcomes and internal consistency for the parent scores.

\begin{tabular}{|c|c|c|c|c|c|c|}
\hline \multirow{2}{*}{ Score } & \multicolumn{3}{|c|}{ Reliability data } & \multicolumn{2}{|c|}{ Median (interquartile range) } & \multirow{2}{*}{ Target score/response } \\
\hline & ICC & $95 \% \mathrm{CI}$ & Cronbach's alpha & Time 1 & Time 2 & \\
\hline \multicolumn{7}{|c|}{$\begin{array}{l}\text { Food availability } \\
\end{array}$} \\
\hline Sweet beverages & $0.86^{* *}$ & $0.76-0.91$ & 0.60 & $13(10-15)$ & $12.5(10-15)$ & $\geq 12$ (less than weekly each item) \\
\hline Non-core foods & $0.81^{* *}$ & $0.7-0.89$ & 0.78 & $20(17-23)$ & $20(17-23)$ & $\geq 21$ (less than weekly each item) \\
\hline Fruit and vegetables & $0.61^{* *}$ & $0.42-0.75$ & 0.13 & $13(12-14)$ & $13(12-14)$ & $\geq 12$ (weekly or more often each item) \\
\hline \multicolumn{7}{|c|}{ Healthy eating } \\
\hline Healthy attitudes & $0.55^{* *}$ & $0.34-0.70$ & 0.35 & $22(19-24)$ & $22(20-24)$ & $\geq 24$ (agree/strongly agree each item) \\
\hline Healthy rules & $0.77^{* *}$ & $0.63-0.86$ & 0.55 & $42(39-45)$ & $42(38-45)$ & $\geq 40$ (often/always each item) \\
\hline \multicolumn{7}{|c|}{ Healthy eating behaviour } \\
\hline Serves of fruit & $0.80^{* *}$ & $0.69-0.88$ & $\mathrm{~N} / \mathrm{A}$ & $2(1-2)$ & $2(1-3)$ & 2 or more ${ }^{\mathfrak{s}}$ \\
\hline Serves of vegetables & $0.86^{* *}$ & $0.77-0.91$ & $\mathrm{~N} / \mathrm{A}$ & $3(1-4)$ & $3(2-4)$ & 3 or more ${ }^{\S}$ \\
\hline Drink when thirsty & $0.92^{* *}$ & $0.88-0.95$ & $\mathrm{~N} / \mathrm{A}$ & $6(6-6)$ & $6(5-6)$ & Water ${ }^{\S}$ \\
\hline \multicolumn{7}{|c|}{ Knowledge of healthy eating } \\
\hline Fruit & $0.61^{* *}$ & $0.41-0.75$ & $\mathrm{~N} / \mathrm{A}$ & $2(2-2)$ & $2(2-2)$ & $1-2 /$ day $^{\S}$ \\
\hline Vegetable & $0.66^{* *}$ & $0.49-0.78$ & N/A & $3(2-3)$ & $3(2-3)$ & $3-5$ serves per day ${ }^{\S}$ \\
\hline \multicolumn{7}{|c|}{ Activity } \\
\hline Attitude activity & $0.74^{* *}$ & $0.59-0.83$ & 0.46 & $24(22-28)$ & $26(22-28)$ & $\geq 28$ (agree/strongly agree each item) \\
\hline Rules activity & $0.67^{* *}$ & $0.50-0.79$ & 0.21 & $11(9-12)$ & $11(9-12)$ & $\geq 12$ (often/always each item) \\
\hline \multicolumn{7}{|c|}{ Other } \\
\hline Money & $0.37^{*}$ & $0.13-0.54$ & N/A & $2(2-2)$ & $2(2-2)$ & $\geq 3$ (disagree/strongly disagree) \\
\hline Breastfeeding & $0.71^{* *}$ & $0.56-0.82$ & N/A & $2(2-2)$ & $2(2-2)$ & $\geq 3$ (disagree/strongly disagree) \\
\hline $\begin{array}{l}{ }^{*} P<0.05 . \\
{ }^{*} P<0.001 . \\
{ }^{*} n \text { varied from } 57 \text { to } 60 v \\
{ }^{4} \text { As per Australian Guid } \\
\text { N/A: not applicable. }\end{array}$ & $\begin{array}{l}n \text { n fo } \\
\text { o Hea }\end{array}$ & $\begin{array}{l}\text { tened be } \\
\text { ating [15 }\end{array}$ & e score 53. & & & \\
\hline
\end{tabular}

TABLE 4: Reliability demonstrated by intraclass correlation coefficient (ICC) and 95\% confidence intervals (CI) for the teacher outcomes and internal consistency for the teacher scores.

\begin{tabular}{|c|c|c|c|c|c|c|c|}
\hline \multirow{2}{*}{ Score } & \multicolumn{3}{|c|}{ Reliability data } & \multicolumn{2}{|c|}{ Median (interquartile range) } & \multirow{2}{*}{$N$} & \multirow{2}{*}{ Target score/response } \\
\hline & ICC & $95 \% \mathrm{CI}$ & Cronbach's alpha & Time 1 & Time 2 & & \\
\hline \multicolumn{8}{|c|}{ Child exposure } \\
\hline Healthy eating & $0.86^{* *}$ & $0.67-0.94$ & 0.61 & $9(6-10)$ & $9(7-12)$ & 20 & $\geq 15$ (weekly, some, agree as relevant) \\
\hline Fruit and vegetables & $0.77^{* *}$ & $0.52-0.90$ & 0.91 & $7.5(5-11)$ & $7(5-13)$ & 22 & $\geq 16$ (weekly each item) \\
\hline Physical activity & $0.67^{* *}$ & $0.38-0.84$ & 0.58 & $21.5(19-26)$ & $22(19-25)$ & 23 & $\geq 30$ (weekly, some, agree as relevant) \\
\hline Water & $0.82^{* *}$ & $0.63-0.91$ & $\mathrm{~N} / \mathrm{A}$ & $5(4-5)$ & $5(5-5)$ & 26 & Used daily \\
\hline \multicolumn{8}{|c|}{ Teacher skills/attitudes } \\
\hline Healthy eating & $0.71^{* *}$ & $0.40-0.88$ & $0.60(n=24)$ & $4(4-6)$ & $5(5-5)$ & 24 & $\geq 7$ (some, yes as relevant) \\
\hline Fruit and vegetable & $0.61^{* *}$ & $0.30-0.80$ & 0.11 & $23(21-24)$ & $22(22-23)$ & 26 & $\geq 24$ (agree each item) \\
\hline Physical activity & $0.56^{*}$ & $0.11-0.82$ & $0.22(n=23)$ & $25(24-27)$ & $24(23-26)$ & 16 & $\geq 27$ (some, yes, agree as relevant) \\
\hline \multicolumn{8}{|c|}{ School environment } \\
\hline & $0.67^{* *}$ & $0.39-0.84$ & N/A & $3(2-3)$ & $3(2-3)$ & 26 & Agree \\
\hline \multicolumn{8}{|c|}{ Teacher knowledge } \\
\hline Fruit & $0.42^{*}$ & $0.05-0.67$ & N/A & $2(2-3)$ & $2(2-3)$ & 27 & 1-2 serves \\
\hline Vegetable & $0.63^{* *}$ & $0.33-0.81$ & $\mathrm{~N} / \mathrm{A}$ & $3(2-3)$ & $3(3-3)$ & 27 & $3-5$ serves \\
\hline Screen time & $0.53^{*}$ & $0.20-0.76$ & N/A & $2(1-2)$ & $2(2-2)$ & 27 & 2 hours \\
\hline Physical activity & $0.81^{* *}$ & $0.63-0.91$ & N/A & $3(2-3)$ & $2(2-2)$ & 27 & 60 minutes \\
\hline
\end{tabular}

${ }^{*} P<0.05$.

${ }^{* *} P<0.001$.

N/A: not applicable. 
fruit and vegetable intake, water intake, and physical activity. Unlike other scales in the literature, we would not necessarily expect all items to correlate. For example children with a high intake of crisps would not necessarily have a high intake of lollies (both single items in the noncore food score). This could explain the lower than ideal Cronbach's alpha values for some of the scores.

Four parent questionnaires were identified in the literature that had similar ranges (or slightly better) of internal consistency and test-retest reliability observed in this study. The Home Environment Survey [25] is completed by parents and measures how supportive the home environment is of healthy eating and physical activity. Cronbach's alpha for four subscales ranged from 0.66 to 0.84 - and test-retest reliability was high with ICC more than 0.75 for all scales. The Children's Dietary Questionnaire, measuring parent report of child eating patterns, had four subscales with Cronbach's alpha for fruit and vegetable and noncore food subscales ranging from 0.62 to 0.76 with ICC for test-retest reliability ranging from 0.51 to 0.90 which was concluded to be satisfactory [26]. The "Meals in Our Household" questionnaire measured parent report of six domains, including family meal structure and mealtime behaviours. Test-retest reliability was assessed using the Spearman correlation for the six domains, and this ranged from 0.80 to 0.95 , while Cronbach's alpha ranged from 0.39 to 0.93 across the six domains [27]. Similarly, a questionnaire measuring constructs believed to predict fruit and vegetable consumption (in children, completed by parents) had Pearson correlation ranging from 0.61 to 0.84 and Cronbach's alpha from 0.31 to 0.91 [28].

A strength of this study is the report on two questionnaires with multiple scores/indexes that simultaneously measure diet and physical activity environments of children. Many evaluation tools measure healthy eating or physical activity, while these tools measure the two simultaneously. Additionally, these tools are unique because they focus on behaviours, environments and attitudes, all of which have been demonstrated as factors contributing to the obesity epidemic [5]. Hence these two tools have the potential to be used in the evaluation of obesity prevention programs and consequently contribute to the evidence about obesity prevention. The indexes also cover a broad range of domains relevant to healthy eating and activity across the home and school environment and use scores as a way of interpreting information and gaining an overall picture. Tools which simultaneously evaluate environments that children are exposed to at home and school, as well as the attitudes of parents and teachers and diet and activity behaviours of children, are lacking in the literature. The use of an internal consistency analysis in addition to testing test-retest reliability is a strength, as is the participation of parents and teachers from both metropolitan and regional schools.

A notable limitation of the study is the sample size. As previously mentioned, the recommendation for a test-retest reliability study is a sample size of 100 [29]. The sample size for the teacher questionnaire fell well short of this $(n=$ 28 ), and the sample size for the parent questionnaire was also below this $(n=60)$. The sample size of teachers at School 2 was low $(n=4)$ because only teachers of classes participating in the ewba evaluation were asked to participate $(n=8)$. The low sample size has implications for interpreting the results of the study, in particular those for the teacher questionnaire, because a larger sample size results in a smaller confidence interval which means we can be more certain that the true reliability coefficient is close to that which has been calculated [29]. Hence, the reliability of the teacher questionnaires in particular should be interpreted with caution. Despite the recommendation of 100 as the sample size for a test-retest reliability study [29], the sample size for similar studies varies considerably in the literature and the sample size for the parent questionnaire falls within this range. Forty-four parents were used to assess reliability of the "Meals in Our Household" questionnaire [27] and 38 childcare directors completed the "Nutrition and Physical Activity Self-Assessment for Child Care" in a test-retest reliability study [30]. Other studies had a larger sample size to test test-retest reliability, including Gattshall et al. [25] who tested reliability of the "Home Environment Survey" with 156 parents and Randall-Simpson et al. [31] who had 140 parents participate to assess reliability of the "Nutrition Screening Tool for Every Preschooler." In addition, while creation of scores can provide more meaningful and reliable results, important information may be missed or results misinterpreted without some secondary investigation of reliability of individual items such as in the parent attitudes to healthy eating and physical activity scores. A possibility for future research is to test the internal validity of the parent and teacher questionnaires and to retest the reliability of the teacher questionnaire with a larger sample size.

\section{Conclusions}

The Parent and Teacher questionnaires for the ewba Community Programs are a moderately reliable method for assessing child intakes, environments, attitudes, and knowledge associated with healthy eating and physical activity. Similar tools are lacking in the literature. These questionnaires assess relevant information and the scores present this information in a meaningful manner, suggesting that they may be useful in similar settings to evaluate similar obesity prevention programs.

\section{Conflict of Interests}

The authors declare that they have no conflict of interests.

\section{Acknowledgments}

The eat well be active Community Programs were funded by the Government of South Australia, SA Health, and implemented by Southern Primary Health, of Southern Adelaide Health Service, and Murray Mallee Community Health, of Country Health SA. Jim Dollman, Fiona Verity, and Jeremy Moller contributed to the development of the questionnaires, and Mel Haynes undertook preliminary analysis and wrote a first draft. The authors thank all participants who provided data, in particular the schools who agreed to 
participate. A. Magarey contributed to the development of the questionnaires, created the parent and teacher scores, undertook further data analysis, and contributed to the first draft and revisions of the paper. A.Wilson was involved in data collection at School 1 and School 2, contributed to data entry for both schools, and revised versions of the paper. N. Mastersson contributed to development of the questionnaires, and commented on paper drafts. All authors revised and approved the final paper.

\section{References}

[1] “Australian Health Survey: First Results 2011-2012," Canberra, Australia, October 2012, http://www.abs.gov.au/ausstats/abs@ .nsf/Lookup/27D7FFFD3AEE46CCCA257AA30014BFFA? opendocument.

[2] B. A. Swinburn, G. Sacks, K. D. Hall et al., "The global obesity pandemic: shaped by global drivers and local environments," The Lancet, vol. 378, no. 9793, pp. 804-814, 2011.

[3] Y. Wang and T. Lobstein, "Worldwide trends in childhood overweight and obesity," International Journal of Pediatric Obesity, vol. 1, no. 1, pp. 11-25, 2006.

[4] J. Foltz, A. May, B. Belay, A. J. Nihiser, C. Dooyema, and H. Blanck, "Population-level intervention strategies and examples for obesity prevention in children," Annual Review Nutrition, vol. 32, pp. 391-415, 2012.

[5] B. Swinburn, G. Egger, and F. Raza, "Dissecting obesogenic environments: the development and application of a framework for identifying and prioritizing environmental interventions for obesity," Preventive Medicine, vol. 29, no. 6 I, pp. 563-570, 1999.

[6] C. D. Summerbell, H. J. Moore, C. Vögele et al., "Evidencebased recommendations for the development of obesity prevention programs targeted at preschool children," Obesity Reviews, vol. 13, no. 1, pp. 129-132, 2012.

[7] R. A. McKinnon, C. T. Orleans, S. K. Kumanyika et al., "Considerations for an obesity policy research agenda," American Journal of Preventive Medicine, vol. 36, no. 4, pp. 351-357, 2009.

[8] C. Alvaro, L. A. Jackson, S. Kirk et al., "Moving Canadian governmental policies beyond a focus on individual lifestyle: some insights from complexity and critical theories," Health Promotion International, vol. 26, no. 1, pp. 91-99, 2011.

[9] B. Swinburn, C. Bell, L. King, A. Magarey, K. O’Brien, and E. Waters, "Obesity prevention programs demand high-quality evaluations," Australian and New Zealand Journal of Public Health, vol. 31, no. 4, pp. 305-307, 2007.

[10] A. M. Wilson, A. M. Magarey, and N. Mastersson, "Reliability and relative validity of a child nutrition questionnaire to simultaneously assess dietary patterns associated with positive energy balance and food behaviours, attitudes, knowledge and environments associated with healthy eating," International Journal of Behavioral Nutrition and Physical Activity, vol. 5, article 5, 2008.

[11] A. M. Wilson, A. M. Magarey, J. Dollman, M. Jones, and N. Mastersson, "The challenges of quantitative evaluation of a multi-setting, multi-strategy community-based childhood obesity prevention programme: lessons learnt from the eat well be active Community Programs in South Australia," Public Health Nutrition, vol. 13, no. 8, pp. 1262-1270, 2010.

[12] T. Pettman, M. McAllister, F. Verity et al., Eat Well Be Active Community Programs Final Report, SA Health, Adelaide, Australia, 2010.
[13] A. M. Magarey, T. L. Pettman, A. Wilson, and N. Mastersson, "Changes in primary school children's behaviour, knowledge, attitudes, and environments related to nutrition and physical activity," ISRN Obesity, vol. 2013, Article ID 752081, 10 pages, 2013.

[14] T. Pettman, A. Magarey, N. Mastersson, A. Wilson, and J. Dollman, "Improving weight status in childhood: results from the eat well be active community programs," International Journal of Public Health, 2013.

[15] M. Jones, A. Magarey, J. Dollman, F. Verity, N. Mastersson, and E. Clover, Eat Well Be Active Community Programs Evaluation Report Part 1: Baseline Data Collection, SA Health, Adelaide, Australia, 2008.

[16] R. S. McPherson, D. M. Hoelscher, M. Alexander, K. S. Scanlon, and M. K. Serdula, "Dietary assessment methods among schoolaged children: validity and reliability," Preventive Medicine, vol. 31, no. 2, pp. S11-S33, 2000.

[17] D. R. Cox, J. D. Skinner, B. R. Carruth, J. Moran III, and K. S. Houck, "A food variety index for toddlers (VIT): development and application," Journal of the American Dietetic Association, vol. 97, no. 12, pp. 1382-1386, 1997.

[18] M. Arimond and M. T. Ruel, "Dietary diversity is associated with child nutritional status: evidence from 11 demographic and health surveys," Journal of Nutrition, vol. 134, no. 10, pp. 25792585, 2004

[19] D. Feskanich, H. R. H. Rockett, and G. A. Colditz, "Modifying the healthy eating index to assess diet quality in children and adolescents," Journal of the American Dietetic Association, vol. 104, no. 9, pp. 1375-1383, 2004.

[20] A. Smith, E. Kellett, and Y. Schmerlaib, The Australian Guide to Healthy Eating, Commonwealth Department of Health and Family Services, Canberra, Australia, 1998.

[21] Department of Health and Ageing, Australia's Physical Activity Recommendations for 5-12 Year olds, Commonwealth of Australia, Canberra, Australia, 2004.

[22] Department of Health and Ageing, Australia's Physical Activity Recommendations for 12-18 year olds, Commonwealth of Australia, Canberra, Australia, 2004.

[23] R. F. de Villis, Scale Development: Theory and Applications, Sage, Thousand Oaks, Calif, USA, 2nd edition, 2003.

[24] J. Pallant, SPSS Survival Manual, Allen \& Unwin, Crows Nest, Australia, 3rd edition, 2007.

[25] M. L. Gattshall, J. A. Shoup, J. A. Marshall, L. A. Crane, and P. A. Estabrooks, "Validation of a survey instrument to assess home environments for physical activity and healthy eating in overweight children," International Journal of Behavioral Nutrition and Physical Activity, vol. 5, article 3, 2008.

[26] A. Magarey, R. Golley, N. Spurrier, E. Goodwin, and F. Ong, "Reliability and validity of the children's dietary questionnaire; a new tool to measure children's dietary patterns," International Journal of Pediatric Obesity, vol. 4, no. 4, pp. 257-265, 2009.

[27] S. E. Anderson, A. Must, C. Curtin, and L. G. Bandini, "Meals in our household: reliability and initial validation of a questionnaire to assess child mealtime behaviors and family mealtime environments," Journal of the Academy of Nutrition and Dietetics, vol. 112, no. 2, pp. 276-284, 2012.

[28] E. Bere and K. I. Kelpp, "Reliability of parental and self-reported determinants of fruit and vegetable intake among 6th graders," Public Health Nutrition, vol. 7, pp. 353-356, 2003.

[29] D. Streiner and G. Norman, Health Measurement Scales: A Practical Guide to Their Development and Use, Oxford University Press, Oxford, UK, 2003. 
[30] S. E. Benjamin, B. Neelon, S. C. Ball, S. I. Bangdiwala, A. S. Ammerman, and D. S. Ward, "Reliability and validity of a nutrition and physical activity environmental self-assessment for child care," International Journal of Behavioral Nutrition and Physical Activity, vol. 4, article 29, 2007.

[31] J. A. Randall Simpson, H. H. Keller, L. A. Rysdale, and J. E. Beyers, "Nutrition screening tool for every preschooler (NutriSTEP): validation and test-retest reliability of a parent-administered questionnaire assessing nutrition risk of preschoolers," European Journal of Clinical Nutrition, vol. 62, no. 6, pp. 770-780, 2008. 


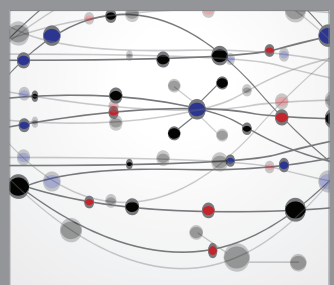

The Scientific World Journal
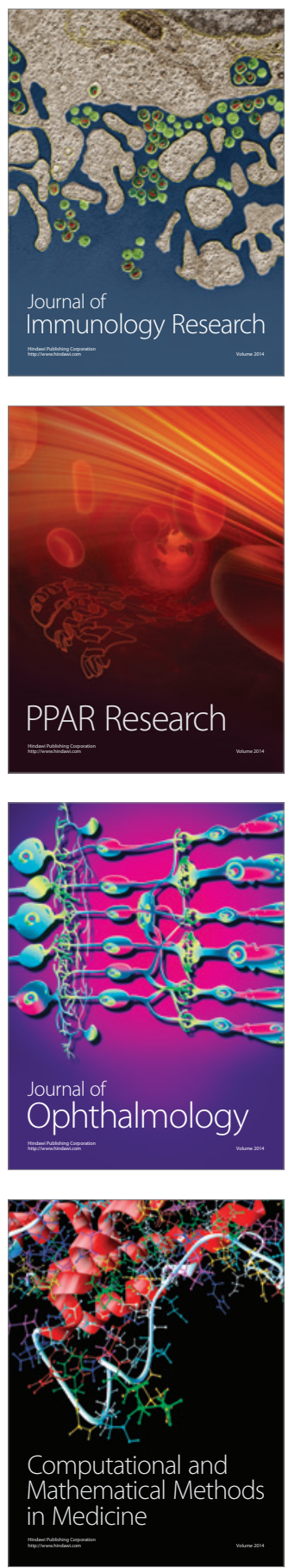

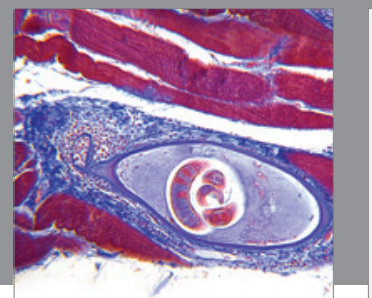

Gastroenterology

Research and Practice
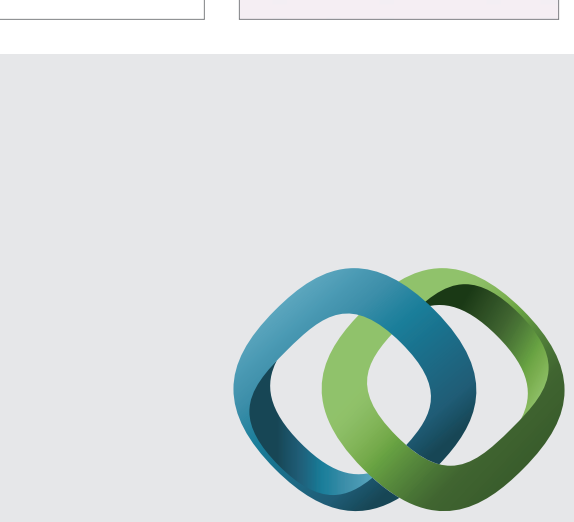

\section{Hindawi}

Submit your manuscripts at

http://www.hindawi.com
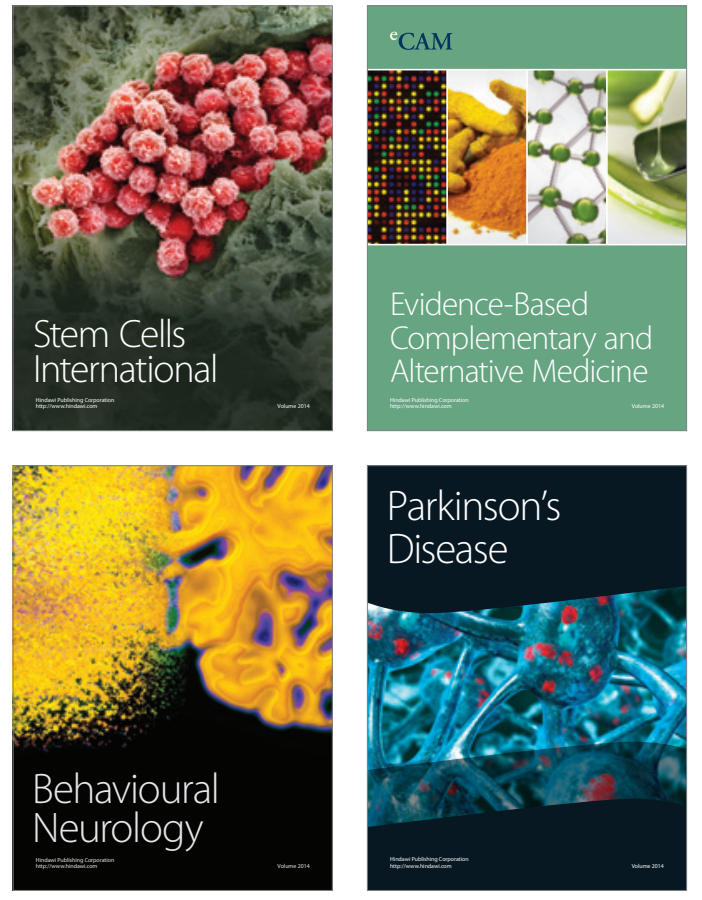
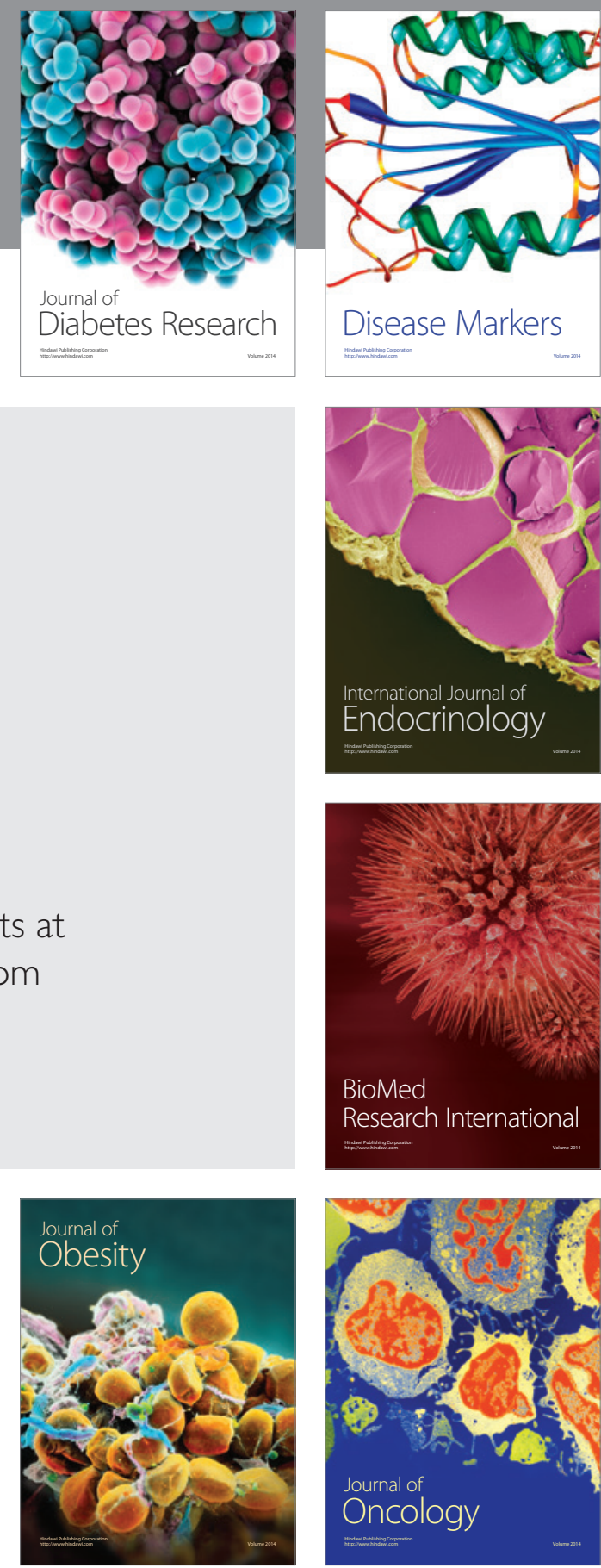

Disease Markers
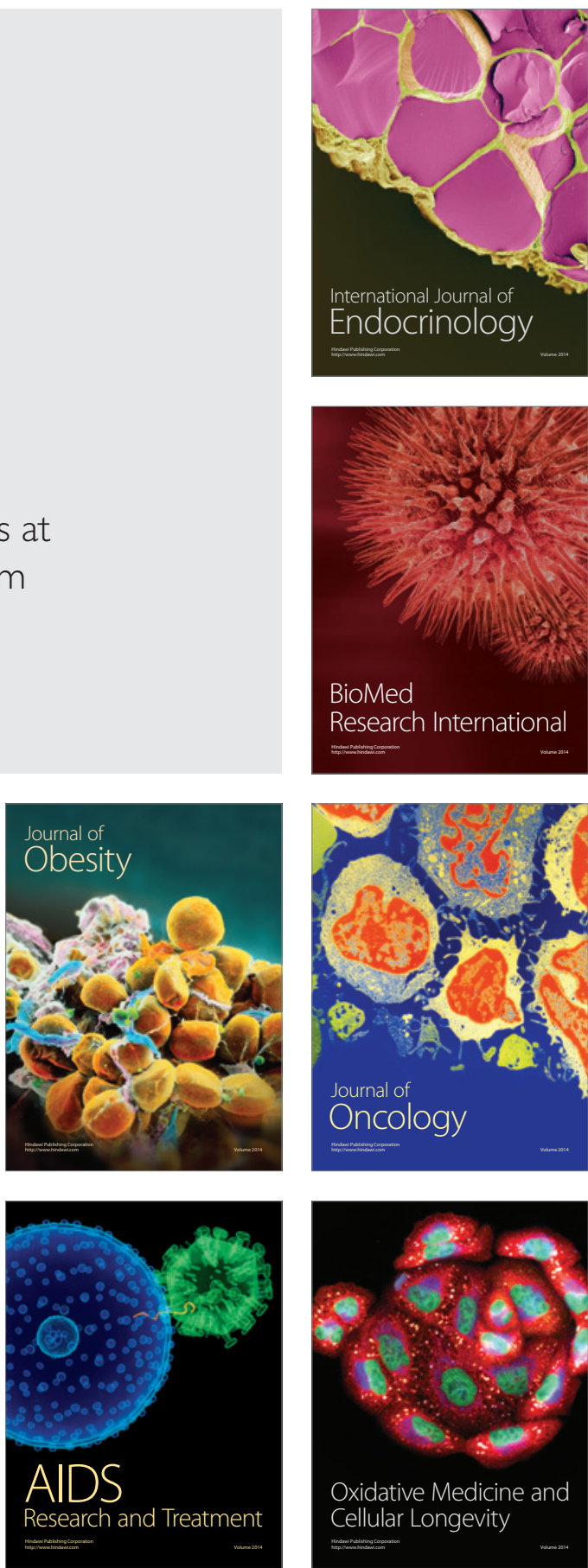